\title{
Winter lightning activity in specific global regions and implications to wind turbines and tall structures
}

\author{
Victor March \\ Gamesa Innovation \& Technology \\ Pamplona, Spain
}

\author{
Joan Montanyà, Ferran Fabró, Oscar \\ van der Velde, David Romero, \\ Glòria Solà, Modesto Freijó \\ Universitat Politècnica de Catalunya \\ Terrassa, Spain
}

\author{
Nicolau Pineda \\ Meteorological Service of Catalonia \\ Barcelona, Spain
}

\begin{abstract}
The paper presents winter lightning maps on specific regions in the northern hemisphere. Four different degrees of winter lightning activity are defined based on information derived from Japanese case. Based on this reference case it is possible to determine regions where winter lightning can be a threat to specific structures. Guidance on risk assessment to tall structures and wind turbines are described as well.
\end{abstract}

Winter Lightning, risk assessment, wind turbines, tall structures

\section{INTRODUCTION}

Storms and lightning differ from one geographic area to another. In Europe, lightning activity is concentrated during the "warm season" since it is related to solar heating and availability of atmospheric water vapor [1-2]. Poleman et al. [1] found that winter months account only for $3 \%$ of the annual lightning in Europe. But, although globally lightning activity associated to winter thunderstorms is low, these storms can produce very energetic lightning events and a large amount of damage (e.g. [3]). Moreover, winter storms present the most favorable conditions for the initiation of upward lightning flashes from sensitive tall structures such as wind turbines (e.g. [4]) and for flying aircraft (e.g. [5]). A recent study by Honjo [6] of a sample of 506 lightning currents to wind turbines in Japan concludes that winter lightning currents tend to feature longer duration currents, often bipolar, and that some particular wind turbines can be struck by lightning repeatedly in short periods of time. From the data, in about $5 \%$ of the cases the charge transferred by lightning exceeded $300 \mathrm{C}$. Wang and Takagi [7] analyzed a sample of 100 records and summarized that $67.6 \%$ of the cases presented negative polarity, $5.9 \%$ presented positive polarity and $26.5 \%$ presented bipolar currents. In that study they also found that about a $50 \%$ of the cases were selfinitiated by the wind turbine and approximately the same percentage of flashes were initiated by other lightning activity. The authors noted that active thunderstorms produced more induced lightning than those storms with lower lightning activity. Additionally in [7] noted that strong wind conditions common in winter storms may favour upward lightning initiation.

The goals of this paper are a) to adjust winter lightning degrees in Japan of the method described in previous paper [8] with distribution found by Japanese researchers [9] b) in a second step to present degree of winter lightning in different regions of the world and identify regions where winter lightning activity may be as high as in the west coast of Japan and c) to discuss application of this new information on Risk Assessment.

\section{GLOBAL WINTER LIGHTNING MAP}

The background for this analysis is described in more detail in [8]. In order to process the maps we used a simple criterion to define winter lightning conditions. The criterion to classify a lightning stroke as winter lightning is if it occurred in meteorological conditions with temperatures equal or lower than $5^{\circ} \mathrm{C}$ at the $900 \mathrm{hPa}$ level (about $1 \mathrm{~km}$ above mean sea level). Temperature data at this pressure level is obtained on a $1^{\circ} \times 1^{\circ}$ grid from ECMWF Re-Analysis (ERA-Interim). Global lightning data were provided by the World Wide Lightning Location Network (WWLLN) [10]. The period of analysis correspond to five years (2009-2013). The average number of winter thunderstorm days per year $\left(\mathrm{N}_{\mathrm{WT}}\right)$ is presented in Figure 1.

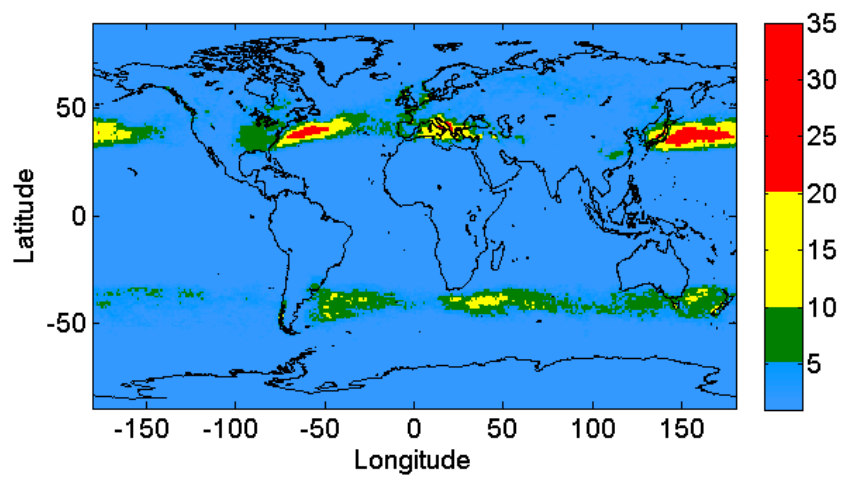

Figure 1. Global winter lightning map (color scale indicates number of thunderstorm days during the non-convective season as defined in [8].

\section{WINTER LIGHTNING ACTIVITY IN SELECTED REGIONS}

As described in previous section, winter lightning map in different regions is performed by means of number of thunderstorm days in the different cells along the world. The analysis in this section is performed by considering the Japanese case as a reference case. In Japan, winter lightning phenomenon has been widely analyzed by field measurement campaigns that lead to a general winter lightning map. This 
map splits the Japanese islands in 4 different regions regarding their winter lightning activity (Figure 2). In this Figure 2, the red region refers to severe winter lightning region, yellow region to medium degree, green to low degree and blue to no activity.

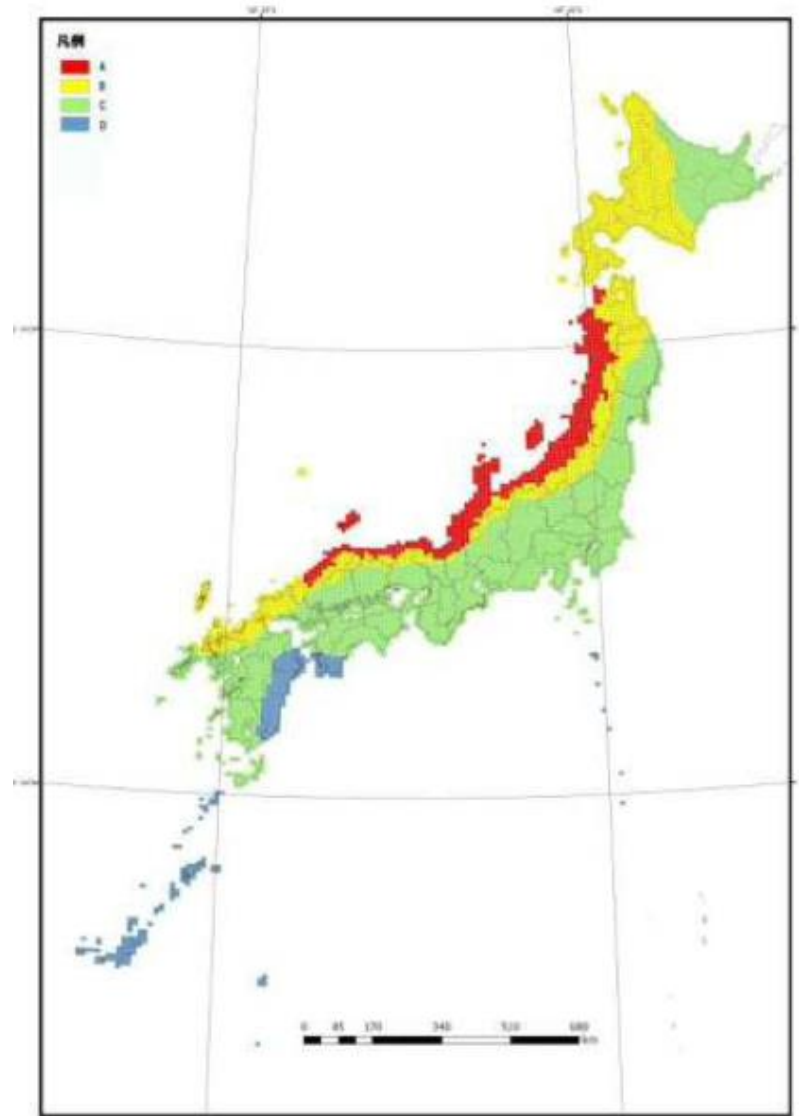

Figure 2. Winter Upward lightning activity risk map with four identified regions, A: severe, B: Medium, C: low and D: no winter lightning. Source NEDO Report Figure 7.3.1 [9].

In our approach, and as a first step, we need to adjust the ranges of the number of thunderstorm days along Japanese islands in order to correlate the winter lightning activity with the distribution resulted from the Japanese experts in the NEDO report [9].

\section{A. Japan}

As said before, Japanese winter lightning activity is by far the most analyzed case. It has been deeply analyzed in numerous papers, e.g. [11]. In Japan, national standard for wind turbines as well as other research papers and report [9, 12] have identified the west coast as the most severe exposed to winter lightning. In this way, additional requirements to the lightning protection system are needed. For example, airterminations must be submitted to higher electric charge during arc entry tests.

Japanese winter lightning area in the west coast of Japan is used as reference of "severe winter lightning". In a second step, we have adjusted the second range (region B in Figure 2) to be concentrated towards the east from region $A$ and in the north and south of the Japanese islands. The third region (region $\mathrm{C}$ in Figure 2) shall be present in the rest of the islands except in the south east of the islands where winter lightning seems to be not present (this is region D in Figure 2).

This resulted in the following ranges: the lowest from 0 to 4 days (no WL activity); a second ranging from 5 to 10 (low WL activity); a third from 11 to 20 (medium WL activity); and a fourth with 21 thunderstorm days and above (severe WL activity). The results for the Japanese area are plotted in Figure 3. As it can be seen, the severe WL activity along the west coast fits very well with the WL map in Figure 2 adapted from NEDO report [9]. Additionally, this area describes a very thin profile along the west coast with maximum activity in the central regions (Honshu island) and decreases immediately to a "medium WL activity" when moving towards the east and towards the coastal north and south regions respect to this severe WL region. Finally, blue region in the south east of the islands it is also found (no winter lightning).

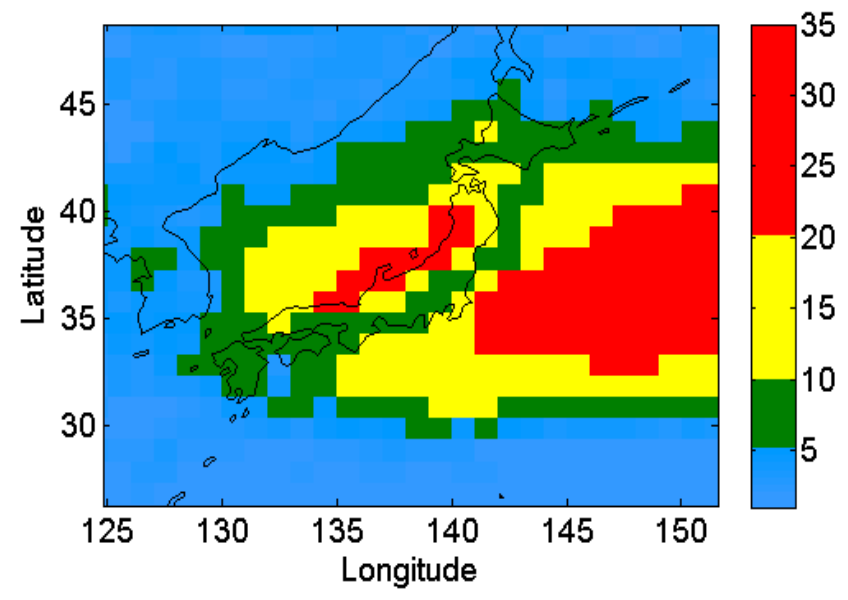

Figure 3. WL activity for Japan based on adjusting the range for the west coast. Color scale indicates number of winter thunderstorm days.

Once we have adjusted these ranges, in the text below we analyze the result for 3 different cases in the northern hemisphere: Mediterranean Sea, European Atlantic shore and the U.S.

\section{B. Mediterranean Sea}

Mediterranean Sea has also been identified in some analysis as an area with high activity during the nonconvective months [2]. Using the same ranges as presented for the Japanese case, Figure 4 shows the resulting winter lightning activity along this area. It is very interesting to see, that two areas can also be classified as "severe WL activity", the first along the half south western coast and a second extending along the Adriatic coast from Croatia to Greece. And that in general, winter lightning activity can be expected in tall structures erected along the Mediterranean Sea. 


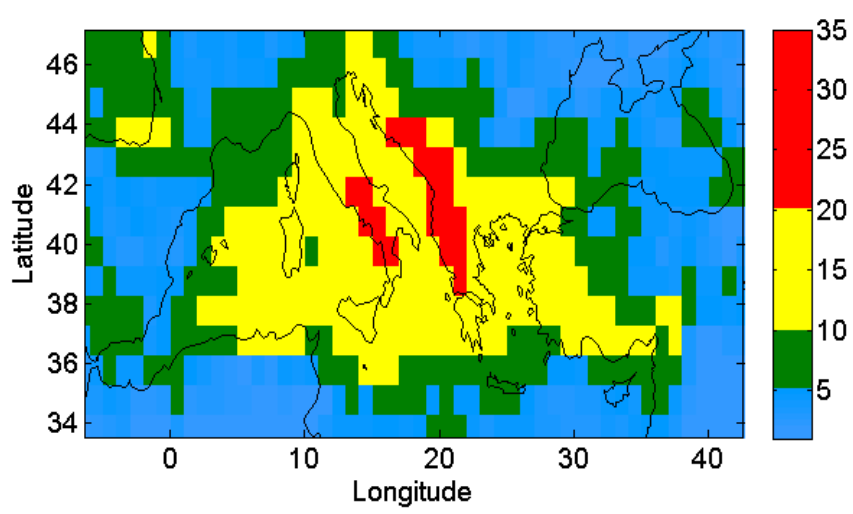

Figure 4. Resulting WL activity along Mediterranean Sea using same adjustment as in Figure 3. Color scale indicates number of winter thunderstorm days.

\section{European Atlantic shore}

Europe also disposes of an area in which winter lightning activity is present in low and medium degrees. It is present along all the Atlantic shore from Portugal to Norway. As can be seen in Figure 5, only the west coast from England, which is shielded from the open Atlantic Ocean, does not present winter lightning as it is concentrated along the Atlantic shore in Ireland. Highest winter lightning activity is presented in along Biscay Gulf and small regions in France (Nantes and Normandy), the Netherlands and Germany. In general, winter lightning activity expected in this region, is lower than the one for the Mediterranean Sea.

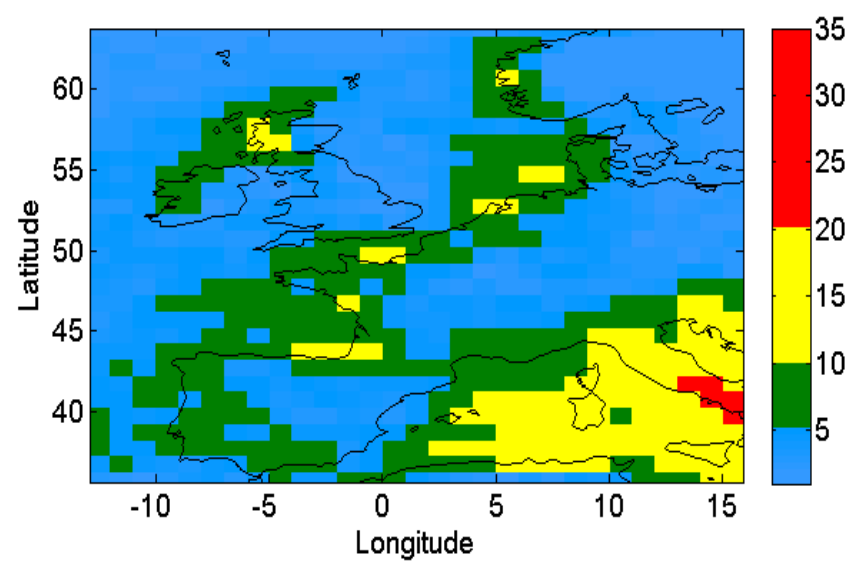

Figure 5. Resulting WL activity along European Atlantic shore using same adjustment as in Figure 3. Color scale indicates number of winter thunderstorm days.

\section{North-America}

Results for north-America are presented in Figure 6. In north-America, western coast presents low winter lightning activity in northern latitudes which include Oregon and Washington in the US and British Columbia in Canada. Half east part of US as well as in some parts of Ontario and Québec in Canada low winter lightning is also present. There is no signs of winter lightning activity in half west of the US and Canada. Orville [13], in 1989, studied winter lightning along the east coast of the US. He found high cloud-toground lightning activity along the coast and described the cause. A more detailed description of the cause for this distribution can be found in [8]. But from a qualitative point of view low winter lightning activity can be found along east region and western coastal regions from latitudes ranging from 40 to 60 .

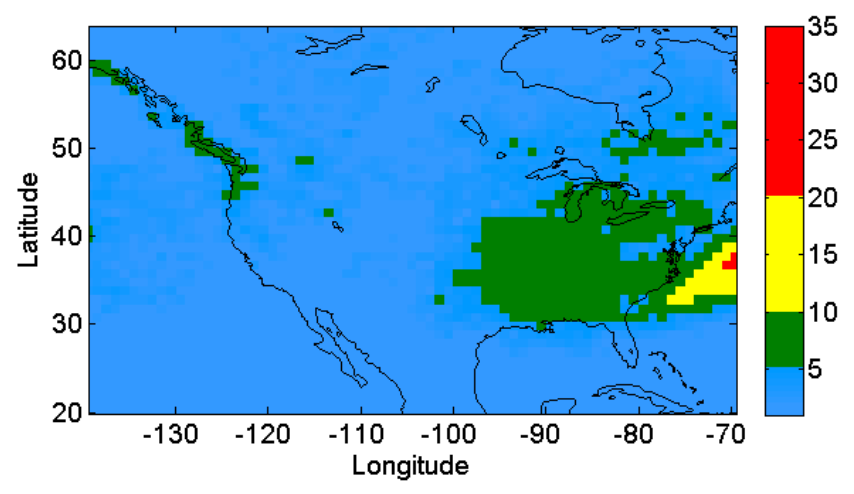

Figure 6. Resulting WL activity along United States using same adjustment as in Figure 3. Color scale indicates number of winter thunderstorm days.

\section{RISK ASSESSMENT TO TALL STRUCTURES AND WIND TURBINES}

\section{A. Winter lightning activity}

Winter lightning is a completely unknown phenomenon from a global perspective. In Japan, winter lightning phenomenon has been widely analyzed because the interaction it has with wind turbines. As presented in Figure 2, Japanese researchers and Engineers have divided the Japanese islands in different winter lightning regions. But, unfortunately up to now, this constitutes an isolated case. In the rest of the world, winter lightning phenomenon is completely unknown and regions are not established as in Japan. Moreover, winter lightning activity has shown several signatures, such as "hot spots" close to tall structures, repetitive upward lightning activity in short time periods or flashes with an excess of electric charge. From a lightning protection point of view, the first step in any Risk Assessment is to determine the lightning activity in the region. This is usually done by means of flash densities from lightning location systems, which basically detect downward lightning. But, winter lightning enhances upward lightning activity, and then, this analysis is not valid to determine the threat of winter lightning. In this way, it is necessary to dispose of a worldwide winter lightning map. The method presented in a previous paper [8], and validated in this paper using Japanese case as reference seems to be valid in order to have a global qualitative approach. This is similar as old isokeraunic maps still described in some standards [14]. The user can use the maps in the regions presented in this paper as a qualitative approach of winter lightning activity in the region where a tall structure or a wind turbine is erected or planned to be erected. 
Risk assessment is described in IEC standards [15-16]. But in the case of tall structures such as wind turbines it is needed to include winter lightning as one main parameter. The non-inclusion of this phenomenon can lead to high errors. As an example, in Japan, winter lightning causes more than $99 \%$ of the flashes to wind turbines along the west coast.

In Spain, it was monitored a wind turbine during two consecutive years [17]. One of the years had a high winter lightning activity while the in the other year, winter lightning was very low. It was found that the number of lightning to the structure increased three times with a similar total flash density (based on information from LLS). In another analysis on 18 wind farms during 4 years in the north of Spain [18], the results show that there is an increase of lightning activity close to wind turbines in years were winter lightning activity is present. These examples show the importance of considering winter lightning in any analysis as a potential cause of abnormal performance of the lightning protection system. In some analysis performed in the wind industry, the lack of considering winter lightning can produce high estimation errors, as can be the case in Japan, Italy, Croatia, Atlantic shore or east part of the US.

\section{B. Topographic effect and structure influence in total winter lightning activity}

The maps presented in section III must be combined with two important issues. First of all, the local topography can play a fundamental role. As winter lightning promotes the inception of upward lightning from a structure, the properties of the terrain where the structure is erected must also be considered. In this way, the complexity of the terrain, i.e. the shape and height of a mountain or a hill and the height above sea level can highly influence the activity in any fixed structure. And secondly, the own height of the structure can also influence the final local activity on it. In other words, the local electric field along the structure is highly influencing the winter lightning activity. For example in [17], is presented a case in the north of Spain, in which the erection of a 180 meters wind turbine in a mountain top, highly increased the local upward lightning activity during years with winter lightning activity. According to Figure 5, the wind turbine was included in a "low winter lightning" region. However, the height of the turbine together with the location of the turbine (it was erected on mountain top with a height above sea level of $1100 \mathrm{~m}$ ), triggered a very high winter lightning activity. For example, in February 2013, 9 upward flashes occurred during a 2 hours period.

\section{Quantitative approach of winter lightning activity in a specific site}

In sections IV.A and IV.B, have been presented the two situations that can influence the local winter lightning activity in a specific site. On one hand, the specific site must be placed in a winter lightning region. And secondly, it is needed a tall structure placed on flat or mountainous terrain or even just a structure (even not tall) which is placed in a more complex terrain. Another case is a tall structure placed at a high altitude respect to sea level. These different situations can increase the final winter lightning activity in the site.

- But in any case, it is not an easy task to quantify it. It is needed to develop and validate an algorithm which takes into account and quantifies the influence of the above mentioned parameters. In other words, risk of winter lightning to a structure shall be quantified as:

Where $N_{W T}$ is the number of winter thunderstorms, $H_{S}$ is the height of the structure and $L_{S}$ is the location of the structure including terrain complexity and height above sea level.

Another important thing is that winter lightning is not constant during the years. It can highly vary from year to year. The lack of damages to tall structures and to wind turbines during years with no winter lightning and high percentage of damages during winter lightning period (October to March in the north hemisphere) can guide the task to identify the presence of winter lightning phenomenon in a specific area. For short term predictions this should be taken into account. For example, for more than 20 days per year, it has been considered that winter lightning degree is severe. In some places, it could happen that in two consecutive years, the number of winter thunderstorms could be 9 and 25, being low and severe activity according to our classification. When analyzing any area according to this criterion, the activity during the time period shall be determined for a higher precision. The maps presented in this paper may be accurate for long term predictions, but may differ for short term predictions.

\section{CONCLUSIONS}

In this analysis, we have, for the first time, correlated the degree of winter lightning in Japan with other sites in the north hemisphere. The analysis shows:

- Winter lightning is a global phenomenon and not an isolated case for Japan.

- Method presented in [8] fits with the Japanese winter lightning map from NEDO report [9]

- Degree of winter lightning in some Mediterranean regions is as high as in west coast of Japan. This is the case of southern west coast of Italy and eastern Adriatic coast.

- Along the European Atlantic shore winter lightning is present in low degree with small spots with medium degree.

- East part of the US presents low degree of winter lightning activity as well as coastal areas in Oregon and Washington States and British Columbia (Canada).

Additionally, regarding risk assessment: 
- It is necessary to include winter lightning maps in lightning standards related to tall structures and wind turbines, to have a qualitative approach of the risk due to winter lightning.

- Topographic effects can also enhance the local winter lightning activity in tall structures or wind turbines.

- Quantitative approach of the total winter lightning activity is a difficult task because it is needed to quantify the influence of the particularities of the site and the structure together with winter lightning activity.

\section{ACKNOWLEDGMENT}

This work was supported by research grants from the Spanish Ministry of Economy and Competitiveness (MINECO) AYA2011-29936-C05-04 and ESP2013- 48032C5-3-R.

[1] Poelman, D. R., Schulz, W., Diendorfer G. and Bernardi, M.: The European lightning location system EUCLID -Part 2, Nat. Hazards Earth Syst. Sci. Discuss., 3, 5357-5381, 2015.

[2] Anderson, G. and Klugmann D.: European lightning density using ATDnet data, Nat. Hazards Earth Syst. Sci. Discuss., 1, 6877-6922, 2013.

[3] Yokoyama S., et al.: Lightning protection of wind turbine blades, Electra, 274, 43-45, 2014.

[4] Montanyà, J., van der Velde, O., and Williams, E. R.: Lightning discharges produced by wind turbines, J. Geophys. Res.Atmos., 119, 1455-1462, 2014a.

[5] Wilkinson, J. M., Wells, H., Field, P. R. and Agnew, P.: Investigation and prediction of helicopter-triggered lightning over the North Sea, Met. Apps, 20, 94-106, 2013

[6] Honjo, N.: Risk and its reduction measure for wind turbine against the winter lightning, in Proc. Asia-Pacific Intl. Conf. on Lightning, 2015, pp. 665-670.

[7] Wang, D., and Takagi, N.: Typical characteristics of upward lightning observed in Japanese winter Thunderstorms and Their Physical Implications, in Proc. Intl, Conf. on Atmospheric Electricity, 2011.

[8] Montanyà, J., Fabró, F., van der Velde, O., March, V., Williams, E. R., Pineda, N., Romero, D., Solà, G., and Freijo, M.: Global Distribution of Winter Lightning: a threat to wind turbines and aircraft, Nat. Hazards Earth Syst. Sci. Discuss., doi:10.5194/nhess2015-302, in review, 2016.

[9] NEDO report 20150000000080, "Research and Development of Next-Generation Wind Power Generation Technology for Technology Corresponding to Natural Environment etc. for Measures of Lightning Protection (FY2008-FY2012)," Annual Report of NEDO, Japan (2015-03).

[10] Rodger, C.J., Werner, S., Brundell, J. B., Lay, E. H., Thomson, N. R., Holzworth, R. H. and Dowden, R. L.: Detection efficiency of the VLF World-Wide Lightning Location Network (WWLLN): initial case study, Ann. Geophys., 24, 3197-3214, 2006.

[11] Wada, A., Yokoyama, S., Hachiya, K. and Hirose, T., 'Observational results of lightning flashes on the Nikaho-Kogen wind farm in winter (2003-2004)'. Proc. Int. Symp. High Voltage Eng., Beijing, China, August 2005.

[12] Shindo, T., Shiraishi, H., Sekioka, S., Ishii, M. and Natsuno, D., "Studies of lightning protection design for wind power generation systems in Japan”. CIGRÉ C4.306 2012.

[13] Orville, R.E. "Winter lightning along the east coast", Geophys. Res. Letters. Vol. 17. No.6, pg 713-715, 1990.
[14] IEEE Std 1410-2010. "IEEE Guide for Improving the Lightning Performance of Electric Power Overhead Distribution Lines”, 2011.

[15] IEC 61400-24: 'Wind turbines -Part 24: Lightning Protection', 2010.

[16] IEC 62305-2: 'Protection against lightning - Part 2: Risk Management', 2010.

[17] March, V. 'Upward lightning observations on a wind turbine and its implications to environmental factor for risk assessment'. Proc. AsiaPacific Conf. Lightning Protection, Nagoya, Japan, June 2015.

[18] March. V., 'Lightning exposure assessment on wind farms based on lightning location system (LLS) information', Proc. Int. Conf. on Lightn. And Static Elect. Toulouse, France, Sept. 2015. 